\title{
Girls-Day im Palmengarten
}

Um 9:30 Uhr bin ich am Eingang, mit sieben anderen Mädchen, abgeholt worden. Wir sind zur Schreinerei gegangen und haben Vogelhäuser gebaut. Danach sind wir frühstücken gegangen. Bis 12:30 Uhr durften wir in kleinen Gruppen den Palmengarten besichtigen. Ich bin mit drei anderen Mädchen zum großen Weiher gegangen und zwei der Mädchen sind mit einem Ruderboot gefahren. Als wir dann von einer Führerin abgeholt wurden, sind wir als erstes zu den fleischfressenden Pflanzen gegangen. Danach sind wir durch verschiedene Gewächshäuser gegangen. Dort hat uns die Führerin verschiedene Pflanzenteile gegeben. Diese durften wir essen oder an ihnen riechen. Zum Beispiel haben wir Zimtblüten bekommen, die wir essen durften. Wir haben auch tote Kakteenläuse bekommen, welche wir zerdrücken und zerreiben sollten. Aus den Läusen wurde lila-rote Farbe gewonnen, die zum Färben von Gummibärchen benutzt wird. Um 13:30 Uhr war die Führung zu Ende, wir haben unsere Vogelhäuser geholt und sind nach Hause gefahren.

\section{Jana Lebrecht (12 Jahre)}

Abb. 1: Stolze Besitzerin eines selbstgebastelten Nistkastens.

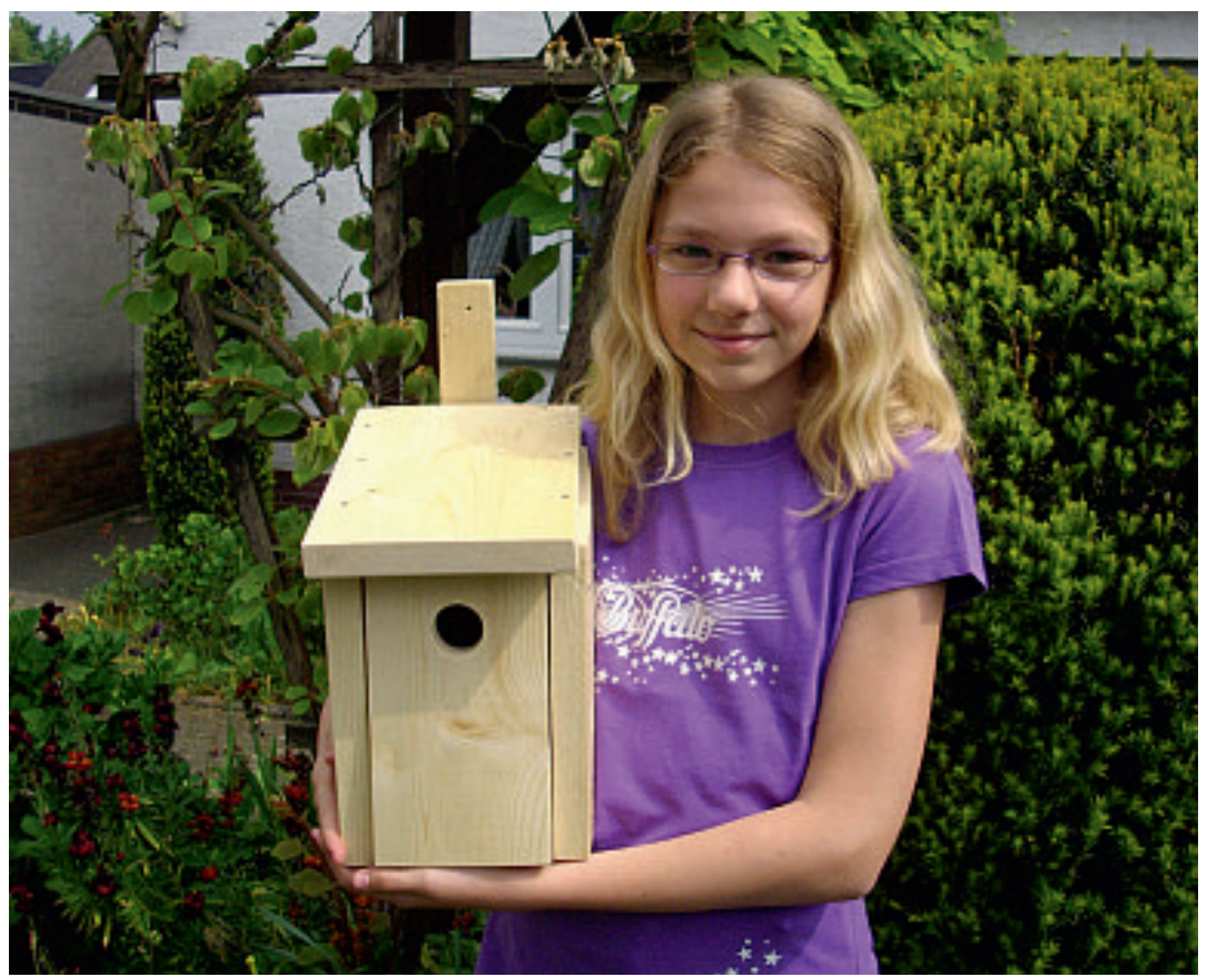

